\title{
Safety and Efficacy of Supracostal Approach for Percutaneous Nephrolithotomy (A Prospective Study)
}

\author{
MOHAB M. ELIBA, M.Sc.; KARIM S.M. SAAD, M.D.; AHMED S.H. EL-ABD, M.D.; \\ MOHAMED O. ABU-FARHA, M.D. and OSAMA M. EL-GAMAL, M.D, F.R.C.S.
}

The Department of Urology, Faculty of Medicine, Tanta University

\begin{abstract}
Background: The management of large kidney stones is still one of today's topics in endourology. Supracostal Percutaneous Nephrolithotomy (PCNL) is found to be a highly effective procedure in treatment of renal calculi. However, many factors are affecting the safety and efficacy of the procedure.
\end{abstract}

Aim of Study: The aim of this study was to evaluate the factors that affect the safety and efficacy of supracostal PCNL in kidney stones.

Patients and Methods: Fifteen patients with renal calculi underwent supracostal percutaneous nephrolithotomy either with single access or multiple accesses. Pre-operative, operative and post-operative data were reported. Multivariate analyses as well as univariate analyses were used to investigate the effects of different variables on residual stones and blood transfusion rate. These factors include age, sex, laterality, body mass index, history of ipsilateral open renal surgery, operative time, and stone density.

Results: The study included 15 patients with mean stone size is $2.5 \mathrm{~cm} \pm 0.6$, all stones were radiopaque with mean HFU $969 \pm 134, \mathrm{R}, 4$ patients had upper calyceal stone (26.7\%), 9 patients had stone pelvis and upper calyx $(60 \%)$, and 2 patients had complex stone. (13.3\%), 9 patients had multiple kidney punctures $(60 \%)$ and 6 patients had single kidney puncture $(40 \%)$, one case had positive signs of hydrothorax intraoperatively $(6.7 \%)$ by fluoroscopy, one case had pelvic perforation $(6.7 \%)$, mean operative time was 105 minutes \pm 0.23 , postoperative chest X-ray revealed positive signs in 2 cases $(13.4 \%)$ with mild symptoms and needed no intervention, 1 case had significant post-operative bleeding (6.7\%) and needed blood transfusion, mean hospital stay time was 2.7 days \pm 1.8 , residual stones were encountered in 4 cases $(27 \%)$.

Conclusion: Supracostal PCNL is a safe and effective procedure for kidney stones more than $2 \mathrm{~cm}$. The stone free rate in the study was related mainly to patient's comorbidities like BMI, stone size and site. Chest complications needed intervention in only one case, later on was completely free.

Key Words: Supracostal - PCNL - Stone free rate - Blood transfusion.

Correspondence to: Dr. Mohab M. Eliba, The Department of Urology, Faculty of Medicine, Tanta University

\section{Introduction}

PERCUTANEOUS Nephrolithotomy (PCNL) was introduced as a minimally invasive modality for treating large renal stones. With improvements in techniques and equipment, in recent years, PCNL is considered as a generally safe management option with a low incidence of complications [13].

Nowadays, PCNL has become the treatment of choice for patients with kidney calculi larger than $2 \mathrm{~cm}$. It has been also, particularly useful for patients with large $(>2 \mathrm{~cm})$ lower calyceal calculi, those with unfavorable lower calyceal anatomy, and patients with stones, in whom Extracorporeal Shockwave Lithotripsy (ESWL) has failed [1-3]

To perform PCNL smoothly and successfully, it is critical to choose a suitable percutaneous access. An ideal PCNL puncture has been described as the one that provides the shortest and straightest access to all calculi, avoids major vessels, bowel and lung, lies along the axis of the calyx and causes minimal parenchymal damage $[4,5]$.

In general, the subcostal access is usually preferred to avoid injury of the pleura or the lung. However, currently many authors have shown that PCNL through a supracostal access approach can clear stones efficiently with a low rate of complications when treating staghorn renal calculi, upper calyceal stones and upper ureteral stones. In addition, the supracostal access usually allows more maneuverability inside the kidney with less torque on the renal parenchyma [6].

In this study we tried to review the safety and efficacy of the supracostal approach in PCNL. 


\section{Patients and Methods}

This study was carried out in Urology Department, Tanta University Hospitals, between August 2016 to September 2017. Fifteen patients were included in this study.

Inclusion criteria: We included only patients with renal stones that were in need for the supracostal access like stones occupying the upper calyx, the pelvis and upper calyx or stones that need multiple accesses including the supracostal one.

Exclusion criteria: We excluded patients with cardiovascular problems that prevent general anesthesia, renal insufficiency, renal transplant or pelvic kidney.

Pre-operative evaluation: Every patient was preoperatively evaluated with complete history taking, general and local examination. Routine laboratory investigations, plain urinary tract film and spiral non contrast CT scan abdomen and pelvis were done. Pre-operative urinary tract infection was treated with culture specific antibiotic.

The procedure: General endotracheal anesthesia with muscle relaxant was used, then the patient was positioned in the lithotomy position, using cystoscopy and under fluoroscopic guidance a $6 \mathrm{Fr}$ open tip ureteric catheter was advanced over the sensor guidewire (Boston Scientific) till it reaches the renal pelvis. Then the ureteric catheter was fixed to 16 Fr urethral catheter and its end was connected to an infusion set that was connected to a sterile syringe containing the contrast material diluted 1:2. The patient was turned to the prone position with a cushion that was placed under the belly. The surgical site was prepared and draped. The contrast material was injected via the open tip ureteric catheter to opacify the collecting system.

Obtaining the supra costal access:

I- Needle used: Chiba needle 18 gauge.

II- Target calyx: Usually upper lateral calyx was our target, but the middle calyx was also punctured in some cases.

III- Site of puncture: In the middle of the 11 th intercostal space, just lateral to mid scapular line.

$I V$ - Relation to respiration: Skin puncture was done during expiration to avoid injury to the lung and pleura, while parenchymal puncture was done during deep inspiration.

Puncture technique: Calyceal puncture was achieved via triangulation technique or bullseye technique according to surgeon preferences. After a calyceal puncture a sensor guide wire was introduced through the needle and manipulated till it passed to the lower calyx or to the ureter. If the manipulation was difficult the wire was allowed to coil in the collecting system to a reasonable length to allow safe dilatation. Another safety guidewire was inserted using a coaxial metal dilator and left to the end of the operation according to surgeon preference. The cases that were in need for multiple accesses were managed by the initial puncture and a guidewire insertion in all tracts before starting dilatation of the primary one. The Alken dilators from 8 to $30 \mathrm{Fr}$ or balloon dilator (Boston Scientific) were advanced over the wire into the collecting system. The Amplatz sheath was advanced over the last dilator or the inflated balloon at pressure between 12-17 ATM. The blood clots were washed away by saline irrigation via a 14Fr nelaton catheter through the Amplatz sheath. The rigid nephroscope (KARL STORZ) (26Fr) was introduced to the collecting system through the sheath to visualize the collecting system and to localize the stone. The stone was disintegrated by ultrasonic lithotripter. Any large fragments were removed by the stone forceps. After removal of the stones and finishing of the procedure a jj stent or ureteric catheter was inserted and 16Fr Foley catheter was inserted as a nephrostomy tube. All patients had a nephrostogram taken at the end of surgery, and lung fields were imaged fluoroscopically with the patient prone, the cases that showed significant hydrothorax were managed by intraoperative insertion of a chest tube by a cardiothoracic surgeon.

Post-operative evaluation: A post-operative chest X-ray was taken immediately after surgery and all the patients were monitored for dyspnea, tachypnea, chest pain or clinically decreased air entry, I.V. fluids were administered in the first post-operative day. Vital data were measured. Pain control was achieved (NSAID) and Antibiotic (ceftriaxone $1 \mathrm{gm}$ per day) was administered. Haemoglobin and haematocrit levels were done 8 hours after operation. Urine output, volume and colour through urethral catheter and the nephrostomy tube were monitored every 8 hours or more frequent in critical cases. Any case with excessive bleeding through the nephrostomy tube, the tube was clamped for 6 hours. Blood transfusion was given in cases with persistent bleeding, haemodynamic instability or significant haematocrit drop. Chest tube was monitored and its output (volume and color) was reported every 8 hours. 
After 24 hours, PUT was done to assess postoperative residual stones in case of radiopaque stones, removal of the urethral catheter and Clamping of the nephrostomy tube and monitoring of pain, fever or urine leakage.

Chest tube was followed-up by erect chest Xray every 2 days and removed after the patient had no respiratory symptoms for at least 1 day and also had a free erect chest X-ray.

Follow-up, after discharge all patients were instructed to call us in case of significant pain, fever, significant change of urine color, or any respiratory discomfort, 1 week later the patients with missed stones were re-evaluated by a new KUB to make decision regarding ESWL for small stone $(>5 \mathrm{~mm})$ and second look PCNL, second look PCNL for large residual stone $<2 \mathrm{~cm}$ was planned 1-2 weeks after operation, $\mathbf{J} \mathbf{J}$ stent was removed after 3-4 weeks or after stone fragmentation by ESWL.

\section{Results}

The study included 15 patients.

1- Age: The study included 15 patients whose ages ranged from 23 to 55 years with a mean age $43.3 \pm 9$ year.

Table (1): Age of studied patients.

\begin{tabular}{ccc}
\hline & Range & Mean \pm SD \\
\hline Age (years) & $23-55$ & $43.3 \pm 9$ \\
\hline
\end{tabular}

2- Sex: The study included 8 males $(53.3 \%)$ and 7 females $(46.7 \%)$.

Table (2): Gender distribution

\begin{tabular}{lc}
\hline & Number of cases (\%) \\
\hline Male & $8(53.3 \%)$ \\
Female & $7(46.7 \%)$ \\
\hline
\end{tabular}

3- BMI: The BMI of studied patients ranged from $25-36 \mathrm{~kg} / \mathrm{m}$ with mean BMI $31.4 \pm 3.2$.

Table (3): BMI of studied patients.

\begin{tabular}{ccc}
\hline & Range & Mean \pm SD \\
\hline BMI & $25-36$ & $31.4 \pm 3.2$ \\
\hline
\end{tabular}

4- Past history:

Table (4): Past history of patients.

\begin{tabular}{lcccc}
\hline & Hypertension & $\begin{array}{c}\text { Diabetes } \\
\text { mellitus }\end{array}$ & $\begin{array}{c}\text { Cardiac } \\
\text { (IHD) }\end{array}$ & $\begin{array}{c}\text { Prior open } \\
\text { pyelolithotomy }\end{array}$ \\
\hline $\begin{array}{l}\text { Number of } \\
\text { cases }(\%)\end{array}$ & $6(40 \%)$ & $6(40 \%)$ & $1(6.7 \%)$ & $3(20 \%)$ \\
\hline
\end{tabular}

5- Laterality: 6 patients had stone on right side $(40 \%)$ and 9 patients had stone on left side $(60 \%)$.

Table (5): Stone laterality.

\begin{tabular}{cc}
\hline & Number of cases (\%) \\
\hline Right & $6(40 \%)$ \\
Left & $9(60 \%)$ \\
\hline
\end{tabular}

6- Stone size: (Maximum diameter on CT): The stone size of studied patients ranged from 2-4 $\mathrm{cm}$ with mean stone size $2.5 \pm 0.6 \mathrm{~cm}$.

Table (6): Stone size of our patients.

\begin{tabular}{ccc}
\hline & Range & Mean \pm SD \\
\hline Stone size $(\mathrm{cm})$ & $2-4$ & $2.5 \pm 0.6$ \\
\hline
\end{tabular}

7- Hounsfield units: The HFU of stones of studied patients ranged from 750-1200 with mean HFU $969 \pm 134$ (all were radiopaque).

Table (7): HFU of stones of our patients.

\begin{tabular}{ccc}
\hline & Range & Mean \pm SD \\
\hline HFU & $750-1200$ & $969 \pm 134$ \\
\hline
\end{tabular}

8- Stone site: Regarding the stone site, 4 patients had upper calyceal stone $(26.7 \%), 9$ patients had stone pelvis and upper calyx $(60 \%)$, and 2 patients had complex stone $(13.3 \%)$.

Table (8): Stone location

\begin{tabular}{llccl}
\hline & $\begin{array}{l}\text { Upper } \\
\text { calyx }\end{array}$ & $\begin{array}{c}\text { Pelvis and } \\
\text { upper calyx }\end{array}$ & $\begin{array}{c}\text { Complex } \\
\text { stone }\end{array}$ & \\
\hline $\begin{array}{l}\text { Number of patients } \\
\%\end{array}$ & 4 & 9 & 2 & 15 \\
& 26.7 & 60 & 13.3 & 100 \\
\hline
\end{tabular}

\section{9- Intraoperative details.}

A- Calyceal puncture: 7 patients had upper calyceal punctures $(46.6 \%), 1$ patients had upper and middle calyceal puncture $(6.7 \%), 5$ patients had upper and lower calyceal puncture $(33.3 \%)$ and 2 patients had middle calyceal puncture $(13.3 \%)$.

Table (9): Calyceal puncture.

\begin{tabular}{lcccc}
\hline & $\begin{array}{c}\text { Upper } \\
\text { calyx }\end{array}$ & $\begin{array}{c}\text { Upper \& } \\
\text { middle } \\
\text { calyces }\end{array}$ & $\begin{array}{c}\text { Upper \& } \\
\text { lower } \\
\text { calyces }\end{array}$ & $\begin{array}{c}\text { Middle } \\
\text { calyx }\end{array}$ \\
\hline Number of patients & $7(46.7 \%)$ & $1(6.7 \%)$ & $5(33.3 \%)$ & $2(13.3 \%)$ \\
\hline
\end{tabular}

B- Intraoperative chest fluoroscopy: Only one case had positive signs of hydrothorax intraoperatively $(6.7 \%)$ including a distinct fluid demarcation laterally along the chest wall from the lung. This case had intraoperative insertion of 
a chest tube in the 5 th intercostal space by cardiothoracic surgeon.

C-Pelvic perforation: Only one case had pelvic perforation (6.7\%).

$D$ - Stenting: 8 cases had ureteric catheters $(53.3 \%)$ and 7 cases needed jj stents $(46.6 \%)$.

E- Nephrostomy tube: Nephrostomy tube was inserted in all cases at the end of the procedure.

Table (10): Summary of intraoperative details.

\begin{tabular}{lcccc}
\hline & $\begin{array}{c}\text { Intraoperative } \\
\text { chest tube }\end{array}$ & $\begin{array}{c}\text { Pelvic } \\
\text { perforation stent }\end{array}$ & $\begin{array}{c}\text { Ureteric } \\
\text { catheter }\end{array}$ \\
\hline $\begin{array}{l}\text { Number of patients } \\
\%\end{array}$ & 1 & 1 & 7 & 8 \\
\hline
\end{tabular}

F-Operative time: The operation time of the studied patients ranged from 90-120 minutes with mean of $105 \pm 0.23$ minutes.

Table (11): Operative time of studied patients.

\begin{tabular}{lc}
\hline & Operative time (minutes) \\
\hline Range & $90-120$ \\
Mean \pm SD & $105 \pm 0.23$ \\
\hline
\end{tabular}

10- Post-operative chest $X$-ray: 2 cases had +ve signs on post-operative erect chest $X$-ray (26.6\%) including obliterated costophrenic angle with fluid between lung fissures. Both patients were asymptomatic with mild fluid collection and did not require any surgical intervention.

Table (12): Post-operative chest X-ray.

\begin{tabular}{lc}
\hline Chest X-ray findings & Number of cases $(\%)$ \\
\hline Free & $13(86.6 \%)$ \\
+ve chest signs & $2(13.4 \%)$ \\
\hline
\end{tabular}

\section{1-Post-operative course:}

A-Post-operative bleeding: 1 case had significant post-operative bleeding $(6.7 \%)$ who needed blood transfusion.

B-Post-operative fever: Fever was encountered in 2 cases $(13.3 \%)$ in the early post operative period and showed good response to medical treatment.

C-Removal of the nephrostomy tube: All nephrostomy tubes were removed $24-48$ hours postoperatively.

$D$ - Post-operative care of chest tube: The chest tube was followed-up every 8 hours and the output was recorded, the chest X-ray was done every 2 days with the tube clamped. On day 5 the chest tube was removed after the chest X- ray was rendered free and the patient had no respiratory symptom with bilateral equal air entry.

Table (13): Complications.

\begin{tabular}{cc}
\hline & Number of cases \\
\hline Complicated cases 3 (20\%): & 1 \\
Massive hydrothorax & 1 \\
Severe bleeding & 1 \\
Pelvic perforation & 13 \\
Non-complicated cases $(80 \%)$ & \\
\hline
\end{tabular}

12- Hospital stay: The hospital stay of studied patients ranged from 1-6 days with mean hospital stay $2.7 \pm 1.8$ days.

Table (14): Hospital stay of studied patients.

\begin{tabular}{lc}
\hline & Hospital stay (days) \\
\hline Range & $1-6$ \\
Average \pm SD & $2.7 \pm 1.8$ \\
\hline
\end{tabular}

13- Residual stone: Residual stones were encountered in 4 cases $(27 \%)$ only one of them had second session PCNL, the other 3 cases underwent ESWL. All of these cases were stone free after the planned procedures.

\section{Discussion}

As a result of technological advances and developments in the new techniques in the surgical treatment of kidney stones, firstly percutaneous stone surgery then flexible ureteroscopy has currently replaced open surgery. The aim of all these efforts is to apply less invasive methods to patients, to provide more effective treatment choices and to enable a return to normal life in the shortest time possible [7].

In the stone guidelines of the American Urological and European Urological associations, the first choice of the treatment algorithm of renal stones larger than $2 \mathrm{~cm}$ is PCNL [7].

However, the decision about the suitable percutaneous access is very critical to perform the operation smoothly and successfully. Currently, it has been shown that the supracostal PCNL can clear stones efficiently with a low rate of complications when treating staghorn renal calculi, upper calyceal stones and upper ureteral stones [8] .

We included 15 patients in this project, 8 of them had 2 accesses including a supracostal one and the rest had a supracostal access only.

All of our cases underwent the supracostal access above 12 th rib and none was above the 11 th 
one. We have selected this approach because of the significant increase in chest complications when the latter approach is used [9].

Munver et al., found that punctures above the 11 th rib have a 16-fold greater risk of intrathoracic complications than the supracostal 12 th rib access and a 46-fold greater risk than subcostal access [9].

On the other hand, in a metanalysis study by Sinha $M$ et al., Seven hundred patients were included for analysis. There were $179(25.5 \%)$ patients in the supra 11 th group, 187 (26.7\%) patients in the supra 12 th group and $334(47.8 \%)$ patients in the infracostal group, thoracic complications showed a graded increase as they progressed from infracostal (1.8\%) to supra 11 th (15.9\%) [10]

Also, Kara $\mathrm{C}$ et al., concluded that percutaneous access via the 10 th and 11 th intercostal space is safe and effective with an acceptable complication rate in the treatment of renal stones and should be attempted in selected cases, as they did not find significant statistical differences in complications between the two studied groups ( 10 th \& 11 th intercostal spaces) [11]

During our surgical procedure we didn't encounter significant intraoperative bleeding. This can be attributed to paying an attention to puncture through the calyceal fornix and not in the infundibulum. It was shown before that the upper polar artery run close to the infundibulum of the upper calyx and it can be injured at this site [10]

Although some of our patients were morbidly obese, we didn't encounter much difficulties with the use of the nephroscope through the supracostal access. This observation was in agreement with Zhou X et al., who used the supracostal approach in patients with morbid obesity [12]

Kekre $\mathrm{N}$ et al., considered morbid obesity as an indication of the supracostal approach especially if associated with high lying kidneys as it was easy to access the kidney using supracostal approach in these patients [13].

Stening $\mathrm{S}$ and Bourne $\mathrm{S}$, treated two morbidly obese patients of $140 \mathrm{~kg}$ and $118 \mathrm{~kg}$ efficiently using supracostal approach PCNL and achieved stone clearance like the rest of the patients in the study with no difficulties [14].

We preferred to use the ultrasonic lithoclast for stone fragmentation as it allows concomitant fragmentation and suction at the same time.
In a study by Karakan $\mathrm{T}$ et al., who compared the safety and efficacy of the use of ultrasonic and pneumatic lithoclast in PCNL, they found that in the ultrasonic lithotripsy group the total stone-free rate was $97.2 \%$, and in the pneumatic lithotripsy group, the total stone-free rate was $91.5 \%$

At the end of the procedure we asked the anesthesia team to check for airway resistance, oxygen saturation and air entry in the ipsilateral lung. In addition, all patients had intraoperative fluoroscopy for chest imaging. With these techniques we were able to detect a case $(6.7 \%)$ of hydrothorax that was in need for chest tube. The use of intraoperative fluoroscopy allowed for intraoperative intervention while the patient was anesthetized. We have also done postoperative chest X-ray for all of our patients, because it is more accurate than the intraoperative fluoroscopy.

However, some authors prefer to do postoperative chest X-ray only in symptomatic patients, to cut the cost of the procedure. In a study by Ogan et al., the detection of pleural fluid after supracostal PCNL was examined by intraoperative fluoroscopy, postoperative chest X-ray and post-operative chest CT. The authors detected hydrothorax in $2 \%(1 / 58)$, $12 \%$ (7/58), $45 \%$ (28/58) of their patients with each of the investigation modality respectively. However, post-operative intervention was necessary only to symptomatic patients. Therefore, they concluded that routine postoperative chest X-ray is not necessary and the clinical symptoms should prompt chest imaging [16]

In a study by Hossain $\mathrm{M}$ et al., hydrothorax was detected in 3/28 (10\%) patients after supracostal PCNL [17].

On the other hand, we have to admit that this complication (hydrothorax) is related to puncturing the parietal pleura during the initial puncture of the supracostal access. Therefore, it can be minimized by puncturing just lateral to the midscapular line and puncturing at the end of the expiration.

In this project we did not encounter cases with hemothorax or pneumothorax. However; in another study by Habibollah $\mathrm{S}$ et al., pneumothorax was reported in 3/123 (2.4\%) intraoperatively. This complication was related to puncturing of the lung during the supracostal access [18].

In the literature, hemothorax was reported in a study by Shoma. A et al., Only in one case of 29 patients with supracostal access (3.4\%). This complication is caused by injury to the intercostal vessels or excessive intrarenal bleeding that reaches 
the pleura. Therefore, it can be avoided by puncturing in the middle of the intercostal space along the upper border of the last rib [19].

In this project we have used $\mathrm{jj}$ stent in cases with pelvic perforation $1 / 15(6.7 \%)$ or significant residual stones $4 / 15(62.7 \%)$ and ureteric catheter was satisfactory in the other cases. According to Gupta et al., pelvic perforation was reported in $6 \%$ of their patients [6].

Gonen $\mathrm{M}$ et al., concluded that tubeless and stentless supracostal PCNL decreases post-operative pain and hospital stay without increasing the incidence of pulmonary complications. They believe that the ureter can provide adequate drainage without stenting after PCNL, and that stentless procedures will not increase the incidence of pulmonary complications [20].

A nephrostomy tube was inserted in all of our cases for drainage of the kidney and monitoring of the urine output. However; Jun-Ou J, et al., performed a randomized controlled trial comparing tubeless supracostal PCNL with standard nephrostomy tube placement in 95 patients, and reported no significant differences in hemorrhage, infection, post-operative pain and hospital stay [21].

Post-operative fever was encountered in (13.3\%) of our patients and showed good response to the medical treatment. This was in agreement with the results of Fan et al., who reported fever in (10\%) of their patients after the supracostal PCNL [9].

Significant post-operative bleeding was detected in only one of our patients $(6.7 \%)$, who needed blood transfusion. In a study by Lojanapiwat B et al., who used supracostal PCNL, post-operative bleeding that needed blood transfusion was encountered in $(2.3 \%)$ of cases [22]

In our study, all patients had a post-operative KUB to detect any residual fragments. In a study made by Osman et al., to test sensitivity of KUB to detect post PCNL residual stones in radiopaque stones, the authors found no statistically significant difference between KUB and other imaging modalities including unenhanced CT scan and ultrasonography in post PCNL residual stones [1] .

In our study, the initial stone free rate was $(83 \%)$. However, we have to admit that the stone free rate is directly related to the stone burden and stone location. This was in agreement with a study by Lang E et al., who had 103 patients, with a stone free rate of $88 \%$ of the patients who were treated by supracostal access PCNL [23].
All our patient had supracostal PCNL in prone position, none had a supine PCNL. However, supracostal PCNL was also feasible in supine position. In a study by Shoma A et al., the authors performed 11 cases with supracostal PCNL in the supine position and they found that the success rate of the operation was $89 \%$ [24].

\section{Conclusion:}

Supracostal PCNL is a safe and efficacious procedure to most patients with low rate of complications in a single or multiple access PCNL and the surgeon should not be reluctant to do it when indicated.

\section{References}

1- OSMAN M., WENDT G., HEGER K., et al.: Percutaneous nephrolithotomy with ultrasonography-guided renal access: Experience from over 300 cases. Br. J. Urol. Int., 96: 8758, 2005.

2- SAXBY F., SORAHAN T., SLANEY P., et al.: A casecontrol study of percutaneous nephrolithotomy versus extracorporeal shock wave lithotripsy. Br. J. Urol., 79: 317-23, 1997

3- KADER K., FINELLI A., HONEY J., et al.: Nephroureterostomy-drained percutaneous nephrolithotomy: Modification combining safety with decreased morbidity. J. Endourol., 18: 29-32, 2004.

4- NISHIZAWA K., YAMADA H., MIYAZAKI Y., et al.: Results of treatment of renal calculi with lower-pole fluoroscopically guided percutaneous nephrolithotomy. Int. J. Urol., 15: 399-402, 2008.

5- WOLF J. and CLAYMAN R.: Percutaneous nephrostolithotomy. What is its role. Urol. Clin. North Am., 24: 43-58, 1997.

6- GUPTA R., KUMAR A., KAPOOR R., et al.: A prospective evaluation of safety and efficacy of the supracostal approach for percutaneous nephrolithotomy. B.J.U. Int., 90: 809-13, 2002.

7- KARAKOYUNLU N., GOKTUG G., SENER N., et al.: A comparison of standard PCNL and staged retrograde FURS in pelvis stones over $2 \mathrm{~cm}$ in diameter: A prospective randomized study, Springer-Verlag Berlin Heidelberg, 00240-015-0768-2, 2015.

8- FAN D., SONG L., DONGHUA X., et al.: A comparison of supracostal and infracostal access approaches in treating renal and upper ureteral stones using MPCNL with the aid of a patented system, B.M.C. Urology, 15: 102, 2015.

9- MUNVER R., DELVECCHIO F.C., NEWMAN G.E., et al.: Critical analysis of supracostal access for percutaneous renal surgery. J. Urol., 166 (4): 1242-6, 2001.

10- SINHA M., KRISHNAPPA P., SUBUDHI S., et al.: Supracostal percutaneous nephrolithotomy: A prospective comparative study, Indian J. Urol., 32 (1): 45-9, 2016.

11- KARA C., DEGIRMENCI T., KOZACIOGLU Z., et al.: Supracostal Approach for PCNL: Is 10 th and 11 th Intercostal Space Safe According to Clavien Classification System? Int. Surg., 99: 857-62, 2014. 
12- ZHOU X., SUN X., CHEN X., et al.: Effect of obesity on outcomes of percutaneous nephrolithotomy in renal stone management, Urol. Int., 98: 382-90, 2017.

13- KEKRE N., GOPALAKRISHNAN G., GUPTA G., et al.: Supracostal Approach in Percutaneous Nephrolithotomy: Experience with 102 Cases, Journal Endourol., 15: 78991, 2001.

14- STENING G. and BOURNE S.: Supracostal Percutaneous Nephrolithotomy for Upper Pole Calyceal Calculi, J. Endo Urol., 12 (4) 359: 362, 1998.

15- KARAKAN T., DIRI A., HASCICEK A., et al.: Comparison of ultrasonic and pneumatic intracorporeal lithotripsy techniques during percutaneous nephrolithotomy, The Scientific World Journal, 604361, 2013.

16- OGAN K., CROWN T., SMITH T., et al.: Sensitivity of chest fluoroscopy compared with chest CT and chest radiography for diagnosing hydropneumothorax in association with percutaneous nephrolithotomy, Elsevier, urology, 62: 988-92, 2003.

17- HOSSAIN M., REGMI S., RAHMAN H., et al.: Safety and efficacy of the supracostal access for percutaneous nephrolithotomy: Our initial experience, Bangladesh. Med. Res. Counc. Bull., 37: 34-8, 2011.

18- HABIBOLLAH S., MOUSAVI B., MEHRABI S., et al.: The safety and efficacy of PCNL with supracostal approach in the treatment of renal stones, Int. Urol. Nephrol., 43: 983-7, 2011

19- SHOMA A. and ELSHAL A.: Nephrostomy Tube Placement After Percutaneous Nephrolithotomy: Critical Evaluation Through a Prospective Randomized Study, J. Urology, 09.042, 2012.

20- GONEN M., CICEK T. and OZKARDES H.: Tubeless and stentless percutaneous nephrolithotomy in patients requiring supracostal access, Urol. Int., 82: 440-3, 2009.

21- JUN-OU J. and LOJANAPIWAT B.: Supracostal Access: Does it affect Tubeless Percutaneous Nephrolithotomy Efficacy and Safety? International Braz J. Urol., Vol. 36 (2): 171-6, 2010.

22- LOJANAPIWAT B. and PRASOPSUK S.: Upper pole Access for Percutaneous Nephrolithotomy: Comparison of Supracostal and Infracostal Approaches. J. Endo. Urol., Volume 20, 2006.

23- LANG E., THOMAS R., R. DAVIS R., et al.: Risks, advantages, and complications of intercostal vs subcostal approach for percutaneous nephrolithotripsy, J. Urol., 74: 751-6, 2009

24- SHOMA A., ERAKY I., EL-KENAWY M., et al.: Percutaneous nephrolithotomy in the supine position: Technical aspects and functional outcome compared with the prone technique, J. Urol., 60: 388-92, 2002.

\section{سلامة وفاعلية منظار الكلى بإستخدام طريق ما فوق الضلوع

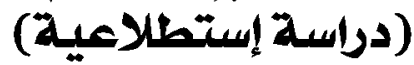

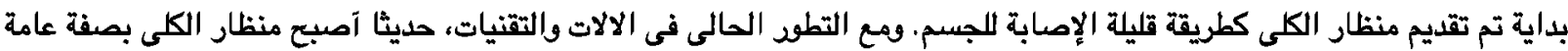

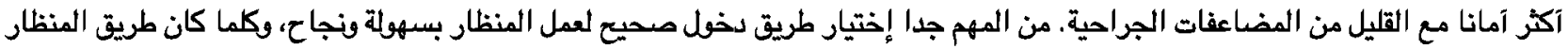

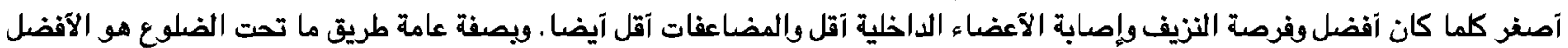

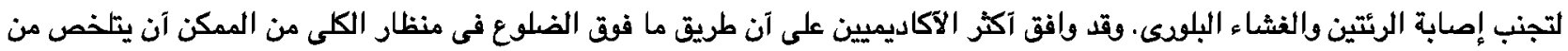

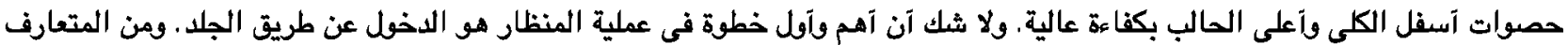

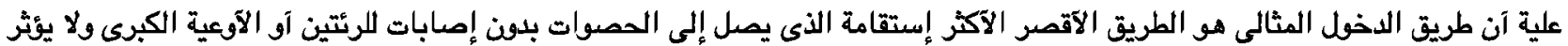

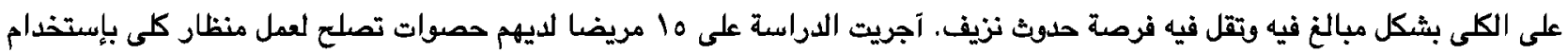

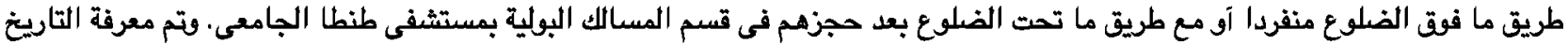

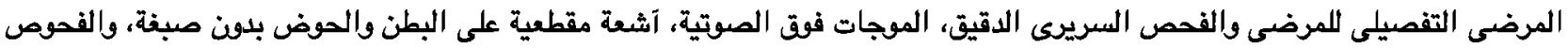

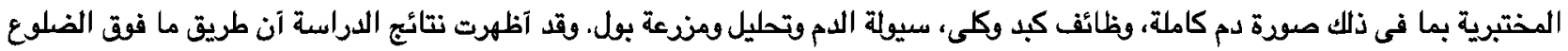

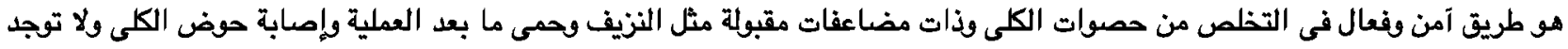
علاقة قوية بين طريق ما فوق الضلوع والمضاعفات ولكن آغلب المضاعفات ناتجة عن عملية دخل المنظار نفسه وليس طريق مات ما فوق الفيق الضلوع.

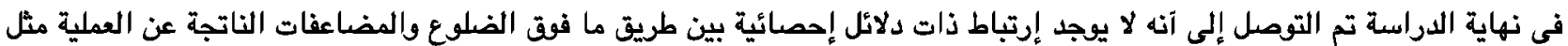

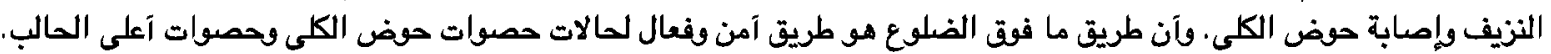

